\title{
Accountability of school stakeholders in ensuring orphaned children's school attendance
}

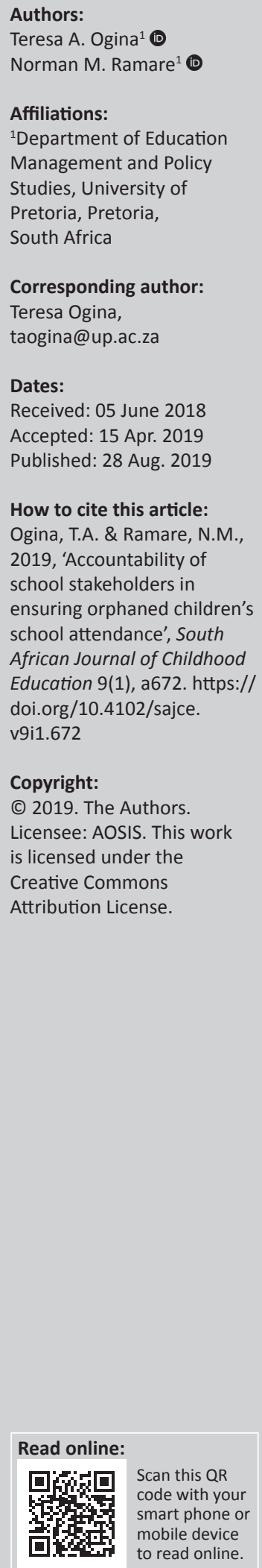

Background: In recent years, there appears to have been more interest than ever in the education of orphaned children, especially in terms of their school attendance. Although some studies have reported on the efforts of caregivers, teachers, government, Non-Governmental Organisations and others in providing the educational needs of orphaned learners, little is known about accountability in terms of their school attendance.

Aim: The aim of this study was to explore the perspectives of school stakeholders on managing the school attendance of orphaned learners.

Setting: This research study was conducted in three primary schools with large numbers of orphaned children and high rates of absenteeism in a district in the Limpopo province, South Africa.

Methods: A qualitative approach was adopted, using semi-structured interviews to collect data from nine participants who were identified through purposive sampling. The participants were class teachers, life orientation teachers and teachers responsible for orphaned learners.

Results: The findings reflect that there is a lack of material resources and emotional support, physical and sexual abuse, little moral responsibility, few family values and inadequate use of resources provided by government and Non-governmental organizations to support the education of orphaned children.

Conclusion: In this article, the researchers argue that the provision of material resources and emotional needs alone do not fully address the problem of the school absenteeism of orphaned learners and suggest a combined accountability of, and consequential measures for, school stakeholders in ensuring the school attendance of orphaned children.

Keywords: teacher; community; partnership; managing; absenteeism; orphaned learners; guardians; caregivers; primary schools; vulnerable.

\section{Introduction}

Recent research indicates that there has been a global increase in the number of orphaned children because of parental AIDS-related deaths as well as other causes such as other diseases, war, natural disaster, violence and accidents, among others (Darago 2016; UNICEF 2017). The death of a parent(s) creates a crisis in the well-being of children, in their education and in their future lives (Mwoma \& Pillay 2016). When children are orphaned, they may no longer have psychosocial support, such as security, love, care, guidance and the stability of loving parents - especially if there are no adult caregivers. The role of caregivers is to promote the health and development of the orphan as well as increase the child's ability to be resilient to poverty and deprivation (WHO 2004). From an educational perspective, a parental death may have a negative impact such as non-school attendance and poor learner performance because of the lack of educational support (Van Rooyen, Frood \& Ricks 2012). Without the help and support of a parent figure, orphaned children are likely to miss the opportunity of attending school and they may develop juvenile delinquent tendencies (UNICEF 2009).

Research has established that orphans are more often absent from school than non-orphans (Operario et al. 2008). Campbell et al. (2016) believe that when orphaned children do not attend school, they miss out on food parcels and clothing material donated by the Non-governmental organizations (NGOs) to the learners at school. The learners also miss opportunities to socialise with other children and the support from welfare organisations. According to the South African Schools Act, learners from Grade 1 to Grade 9 are obliged to attend school up to the age of 16 (Republic of South Africa 1996). Normally, parents or caregivers are held accountable for learners' 
school attendance - as stated in the act (Department of Education, 2010). However, in the case of orphaned children, especially from child-headed households, there are no parent figures to ensure that the children attend school. Non-school attendance of orphaned children at primary level in South African schools means that they fail to exercise their right to basic education, which is entrenched in the constitution. Although the Constitution of South Africa specifies the right of all learners to basic education (Republic of South Africa 2003), the act is silent on the issue of accountability related to the education of orphaned children. There are no stipulations on who should be held accountable for ensuring that the orphaned children attend school.

In this article, the researchers argue that despite children's constitutional rights to basic education, there is a gap regarding who should be held accountable for the school attendance of orphaned children and, more particularly, those without adult caregivers. This article explored the perceptions of teachers regarding the accountability of school attendance of orphaned learners. The questions asked were the following: What are the reasons for the non-school attendance of orphaned children?, What are the challenges experienced when orphaned children are absent from school? and Who should be held accountable for the school attendance of orphaned children?

In this article, the relevant available literature on the school attendance of orphaned children is discussed as well as the different roles played by teachers, schools and the community. The context of the study and the research methodology used are described and the research findings from the qualitative data generated from interviews with the teachers are also discussed. The article concludes with an indication of several implications derived from the findings of this study and it is recommended that schools, communities, government and other stakeholders should collaborate and be accountable to ensure that orphaned children attend school.

\section{Orphans and schooling}

In sub-Saharan Africa, there is a tendency for orphans and other vulnerable children to leave school prematurely (Mwoma \& Pillay 2016). School dropout causes a myriad of problems as children who do not attend school miss the opportunities to learn a variety of skills as well as to obtain knowledge that may help them prepare for the labour market. In many African countries such as Ethiopia (Abebe \& Aase 2007), Kenya (Ombuya, Onyango \& Omolo 2012), Nigeria (Bamgoboye et al. 2017), Zimbabwe (Campbell et al. 2016) and South Africa (Pillay 2012), the factor that causes school dropout and absenteeism in orphaned learners is economic hardship, which at times makes the learners victims of child labour and forces them into prostitution. Such behaviour is out of the necessity to earn a living in the absence of adult caregivers to provide for their economic needs (Ganga \& Maphalala 2013; Smiley et al. 2014; Tagurum et al. 2015). Shann et al. (2013) found that poor nutrition and the threat to the physical safety of orphans and vulnerable children are other reasons for school absenteeism. A study conducted in Tanzania maintains that orphans in primary schools often fail to attend school because they lack basic school-required necessities (Bennell 2010). Similarly, in North-Central Nigeria, Tagurum et al. (2015) identified the lack of school-required necessities, such as school fees and school uniforms as causes of school absenteeism and dropout among orphans and vulnerable children. Smiley et al. (2014) also reported that in Lesotho, the lack of material resources economically disadvantages orphans because they are unable to buy the educational materials needed at school. There are other studies that have reported the absence of adequate social and emotional support as a factor that contributes to orphaned children dropping out of school and developing anti-social behaviour (Ganga \& Maphalala 2013; Mwoma \& Pillay 2015; Smiley et al. 2014). In some child-headed families, orphaned children absent themselves from school to take care of their siblings at home and do household chores because there is no adult caregiver to perform these roles (Moletsane 2013; Pillay 2012).

Other reasons for the high absenteeism rate of orphans and other vulnerable children include fatigue from begging on the streets to support the family and inadequate provision of school transport (Bamgboye et al. 2017; Majanga, Mukonyi \& Vundi 2015). The lack of motivation and poor social relationships between the orphans and the teachers because of stigmatisation are other reasons for the nonattendance of orphaned learners (Wood 2011). Even though the South African Government has adopted strategies that support the education of orphaned learners in terms of no-fee schools, school feeding schemes and the provision of textbooks - among other educational needs, the absence of adult caregivers to provide emotional and material support as well as encouragement and guidance in the education of orphaned children remains a challenge (Mwoma \& Pillay 2016). Similarly, the findings of the Bamgboye et al. (2017) survey of the school attendance of orphans and other vulnerable children in Lagos State in Nigeria suggest that although the enrolment rate of orphans and vulnerable children was high because of the country's free school policy, the rate of regular school attendance was low because of other barriers such as the lack of learning resources, learner motivation, food insecurity and learner involvement in household chores. This article acknowledges that there are barriers to schooling but it focuses on school stakeholder accountability for the school attendance of orphaned children.

\section{Teachers as caregivers}

Internationally, teachers have a legal duty of care for learners who are entrusted to their care for both curricular and extracurricular purposes (Joubert \& Prinsloo 2009). This is according to the educators act in loco parentis on the grounds of original and delegated authority, which emanates from their profession. However, their duty to care does not replace that of parents who remain the primary educators of their children (Joubert \& Prinsloo 2009:145). The duty to care means that teachers assume the responsibility for the safety 
and well-being of learners for as long as they are in their care (Joubert \& Prinsloo 2009). The authors of this current paper are of the opinion that the responsibility of parents to guide and educate their children is an ideal and a distant reality for orphaned children with no adult guardians. For such learners, the teachers' duty to care may go beyond what is legally expected of them, which is teaching and learning. In the absence of parents, teachers may assume some of the roles that are normally played by parents. Teachers are expected to develop and practice caring relationships with orphaned learners (Smedley \& Pepperell 2010). Therefore, schools need to prepare teachers for their pastoral roles; they should be in a position to identify orphaned learners and provide care and support that they are able to offer within the learning environment because of the lack of knowledge and skills required for managing the psychosocial needs of the learners. In a study by Campbell et al. (2016) on the caregiving ability of teachers in rural Zimbabwe, it was found that teachers perceive their roles mainly as teaching, learning and managing school discipline. The teachers in the study (Campbell et al. 2016) did not consider the role of providing care as part of their responsibilities. A possible reason for this is that caregiving is not part of their pedagogical training, and therefore teachers may not have the knowledge, skills and time to manage the needs of vulnerable children. The implication of such perceptions is that the non-academic needs of the learners could go unnoticed and unfulfilled especially in the non-existence of policy guidelines. The absence of policy on caring and the heavy teaching workloads bear limits on the ability of teachers to be caregivers (Campbell et al. 2016). The envisaged policy could focus on care given to learners in the foundation phase as well as orphaned learners with no adult caregivers. Furthermore, apart from knowledge, skills and policy (National Policy Act, 1996), not all teachers have a positive attitude or values that enable them to respond adequately to the emotional, material and educational needs of vulnerable children (Wood \& Goba 2011). This could be because of the different abilities and capabilities of the teachers. Some teachers may be more empathetic than others. Despite the identified challenges, Motsa and Morojele (2016) maintain that teachers may be better able to provide care and support for orphaned children if they have the caregiving skills required in managing the teaching and learning of vulnerable children. Unfortunately, some teacher training courses and programmes do not adequately prepare teachers for the realities of teaching in communities with high numbers of orphans and vulnerable children and where there is a need to provide care, support and protection for such learners (Wood \& Goba 2011). A counter-argument is that not all contextual issues of the school environment can be addressed through teacher preparation programmes. Teachers can adapt to the school environment in which they work and develop certain skills of managing the school situation. Research shows that the school can be a reassuring environment for orphaned children in the absence of caregivers or a safety net for escaping from abusive home situations (Motsa \& Morojele 2016).
There are studies that show that the school environment can contribute to, and be a reason for, school absenteeism among orphaned children. Mohlakwana (2013) and Ombuya et al. (2012) suggest that some orphaned learners do not attend school because they fear being punished for being late for school, for failing tests and for their inability to do homework because of responsibilities at home. Because of their situation at home and what is expected of them at school, some orphaned learners are not able to cope and, as a result, they play truant. Xiaoming et al. (2009) are of the opinion that in China, the academic performance of orphaned children is compromised and low because of anxiety, depression and a lack of time for learning. Such situations contribute to the non-school attendance of orphaned children. Orphaned learners who perform poorly in school also tend to give up on their education (Ombuya et al. 2012). To avoid a high school dropout rate of orphaned children, schools need to manage their school attendance register and make followups on learners who do not attend school to address the causes of absenteeism (Xiaoming et al. 2009). Despite the need to monitor the school attendance of orphaned learners and other vulnerable children, Campbell et al. (2016) found that although some schools had a learner attendance policy, teachers did not monitor the school attendance of children affected by HIV and AIDS. The cited studies suggest that there is a gap in monitoring the school attendance of vulnerable children, despite the advantages of attending school such as recovering from psychological experiences, social interactions and creating a routine in the lives of the learners (USAID 2008). Although there is no doubt about the importance of education for all children, the responsibility of caring for the education of orphaned children cannot be solely the responsibility of teachers. Campbell et al. (2016) state that providing care for orphans and other vulnerable children seems to be an extra burden for teachers and they recommend that school-based caregiving should be enhanced by motivating teachers to take up caring responsibilities, by appointing social workers and other support staff and by having a support system in the school communities. For the authors of this article, the focus is on such care from the perspective of accountability for the school attendance of such children.

\section{Community response to orphaned children}

Community refers to all people living in a specific geographical area who consider themselves as belonging to that place and who relate to one another in some respect (Department of Social Services 2013). In this study, the community refers to the people living in the same area where orphaned learners live and go to school. The community is considered apart from the school stakeholder group. Traditionally, caring for orphans was a shared responsibility that involved an extended family and the community. Earlier studies, undertaken by Abebe and Aase in Ethiopia (2007) and by Foster in Zambia (2002), found that the number of orphaned children was increasing steadily and was overstretching extended family systems, which have been known to care for orphaned children. A trend of changing patterns of 
caregiving for orphans within the extended family safety net has also been observed (Ardington \& Leibbrandt 2010). In a more recent study conducted by Tanga (2013) in Lesotho, it was found that although the traditional extended family support structures still exist, the quality of care was generally poor because of economic constraints, changes in lifestyle and shared values as well as a lack of commitment and enthusiasm from the extended families in playing the role of caregivers. Labour migration, urbanisation and westernisation are other factors that have negatively influenced and weaken the caring role of the extended family for orphans (Tanga 2013).

Apart from socio-economic factors that weaken extended family caring networks, a study conducted in Nigeria by Kazeem and Jensen (2017) suggests that the relationship between orphans and their caregivers in terms of biological or kingship ties determines the extent to which they are likely to attend school. In the study, orphans with closer family and kinship ties to caregivers were found to be more likely to attend school than those not related to the caregivers. In such circumstances, orphaned children in the care of extended families may experience similar problems as orphans from child-headed families with no adult caregiver to account for their school attendance. In Uganda, Dalen (2009) established that child-headed households are shunned by their communities which were traditionally a safety net. The children are often verbally abused and neglected, forced to undertake exploitive work which makes them drop out of school to care for themselves and their siblings (Public Health, 2018). The number of such families is increasing, especially when the grandparents who are traditional caregivers for the orphans die (Bonthuys 2010). In such cases, the orphaned children who care for their siblings in childheaded families miss their schooling, as they need to find ways of providing food for the family and are required to perform household duties (Bonthuys 2010).

Managing the absenteeism of orphaned learners from childheaded families is a challenge because there is no adult figure to accept responsibility for ensuring that they attend school regularly (Mohlakwana 2013). Mwoma and Pillay (2015) identified the need for schools to involve communities and the business enterprises in providing care and support for orphans and vulnerable children. Wood and Goba (2011) also highlight the importance of the collaboration of stakeholders, including the school, parents, the community and external agencies in supporting orphaned and vulnerable children. However, research shows that the systems that once supported orphaned children are weakening because of socio-economic problems, and therefore, in this article, we argued that there is a need for a partnership and support system that includes accountability measures to ensure that orphaned learners attend school regularly. The policy on learner attendance is silent about who should be held accountable for the school attendance of orphaned learners who have no responsible adult caregivers to support the learners to attend school by providing for their needs. Teachers are not given direction on how or who to approach in cases where orphaned children have no adult care (Pillay 2012). From the reviewed literature, there seems to be a gap concerning accountability of regular school attendance of orphaned children.

\section{Context of the study}

The three schools where the research was conducted are in the Mopani District, one of five districts, in the rural area of the Limpopo province. The district includes five municipalities and has a population of 1138063 (Census 2011) and falls under the socio-economic Quintile 2. Each municipality has its own municipal manager and executive mayor and each has its own budget for supporting education by building schools and renovating buildings. The district consists of 24 circuits that include Pedi-, Tsonga- and Vendaspeaking people. The district has one district senior manager, two chiefs or traditional leaders and two leaders who support local education in the form of Indunas (the ones who are seen before meeting the chiefs). A substantial number of community members are unemployed; most adults in the area are farm workers, while others are migrant labourers from neighbouring countries, such as Mozambique, Zimbabwe and Malawi (The Local Government Handbook South Africa 2017). In the community where the research was undertaken, there are four primary schools and four secondary schools. The schools in the Mopani District are mostly Quintile 1 schools, which are no-fee paying schools because of the poverty levels and the inability of community members to pay school fees. Learner performance in the schools in this district is generally average.

\section{Accountability theory}

This article is anchored on the accountability theoretical framework. Accountability theory is concerned with the conditions that require one to be answerable for the assigned or expected task and responsibility (Schlenker 1986). The accountability theory holds organisations and communities answerable for their actions through systems implicitly and explicitly put in place to define goals to be achieved, rules to be followed, acceptable levels of achievement needed to guide behaviour as well as the consequences that can be generated as both process and results of certain actions (Myong, Seongseop \& Wansoo 2012). When applying accountability theory to what teachers do in school to ensure that the needs of the learners are fulfilled so that they can attend school regularly, there is the need to take into consideration that teacher training or preparation courses do not fully equip teachers with knowledge and skills required in fulfilling the needs of the learners. The credibility to accountability theory is a condition of being answerable not only to oneself but also to the audiences interested in certain events and the prescribed ways in which things should be performed (Myong et al. 2012). It means that teachers can only be partially accountable for learner school attendance and that is why in this study, we asked the teachers about how they perceived accountability of other stakeholders against set prescriptions of what should occur or should have 
occurred, in this case the learners' right to education. Schlenker and Weigold (1989) assert that a person's accountability is measured by how closely his or her behaviour matches the prescription as observed by the audience. This study analysed the experiences of the participants on learner absenteeism by exploring the nonexistence policy guidelines on who should be held responsible or accountable and answerable for ensuring that learners attend school. The set prescription being the learners' right to education as stated in the South African School Act and the audience, who are all stakeholders in the education system.

\section{Research methodology}

The research approach in this study was qualitative. The researchers' intention was to explore the experiences of the participants to gain an insight into how they perceive school stakeholders' involvement in managing the school attendance of orphaned learners. The researchers believed that through interviews, as one of the data collection methods in qualitative research, the teachers who participated in the study would be able to describe the challenges they experienced when learners were absent from school as well as how the community and other stakeholders were assisting in managing those challenges. A qualitative research approach was deemed suitable because of its interactive nature and the opportunities of generating in-depth data (Creswell 2013). The approach enabled the researchers to speak directly with the participants and probe their views during the interviews. The research participants had the opportunity to express their experiences from their own perspectives and in their own words. Through a qualitative approach, the researchers draw the meanings and interpretations of the experiences of the participants on the school attendance of orphans.

Purposive sampling is one of the methods used in qualitative research to select participants who have the potential to provide rich data and in-depth descriptions (Cohen, Manion \& Morrison 2011). In this study, purposive sampling was used to select the participants. The researchers in this study targeted the participants who are in a position to give in-depth information about learners' school attendance. The researchers contacted the circuit manager and requested access to three schools with the highest number of orphaned learners and the highest rates of learner absenteeism. The principals assisted the researchers in identifying relevant teachers, such as those responsible for orphaned learners, life orientation teachers who were involved in caring for orphaned learners and class teachers were included because they are responsible for keeping attendance registers. A total of nine teachers were selected from the three schools - three teachers per school.

The researchers used semi-structured individual interviews to collect data from the different participants to generate an in-depth knowledge of their perceptions of managing orphaned learner school attendance. All interview sessions were scheduled to be held at the schools after school hours to ensure that they did not disrupt the participants' school routine. The interviews were conducted immediately after school hours in order not to inconvenience or delay teachers who use public transport at a particular time to go home. The interviews were conducted in English and participants gave the researchers their consent to record the interviews. The interview duration was between 30 minutes and 45 minutes. Each interview was coded with a number for each school and the participants were given code names as indicated in (Table 1) below.

The interviews were transcribed verbatim; the researchers listened to the tapes repeatedly to ensure that their understanding of the participant responses was recorded as accurately as possible. Thick descriptions with direct quotations were obtained from the interview and used to capture the essence of each theme (Crowe, Maree \& Porter 2015).

Data analysis procedures followed an inductive process in which the interview transcripts were coded and categorised. As the data collection method was only interviews, the researcher triangulated multiple perspectives of the responses from the participants in terms of common and dissimilar findings. The patterns of relationship within and between the categories were identified through data triangulation and used to generate themes (Nieuwenhuis 2011).

\section{Ethical procedures}

The participants were told that no incentives would be used to avoid bias and promote voluntary participation. They were also assured that they would be given the opportunity to comment on the interview transcripts in the form of member checking to exclude the data, which they did not want to be used in the research and to make additions to the data already collected. Other strategies used to enhance the credibility of the study were the provision of thick descriptions for readers to decide on the relevance of the research findings to their own context. The researchers also engaged peers in discussion of the study at different stages, namely: the raw data stage and when reporting research findings and making tentative interpretations to obtain their insights and reduce personal bias in the research process. The benefit for the participants was contained in the draft copies of the main findings that they were given and in the recommendations that were made from the study. The participants would be able to use the information to improve their management of the absenteeism of orphaned learners and reflect on their responses to the interview questions.

TABLE 1: Research site and participants.

\begin{tabular}{llll}
\hline School & Teacher & Gender & Teaching experience \\
\hline School 1 & Teachers A & Male & 4 years \\
& Teacher B & Female & 4 years \\
& Teacher C & Male & 5 years \\
& Teacher D & Female & 25 years \\
School 2 & Teacher E & Male & 1 year \\
& Teacher F & Female & 1 year \\
& Teacher G & Female & 1 year \\
School 3 & Teacher H & Male & 21 years \\
& Teacher I & Male & 19 years \\
& Teacher J & Male & 14 years \\
\hline
\end{tabular}




\section{Ethical considerations}

Before conducting the study, permission to access the schools was obtained from the Department of Education. An application letter was sent to the head of the relevant department giving details of the topic to be researched. Upon receiving the permission letter from the province, an application letter and research instrument in the form of an interview guide were submitted to the ethics committee of the university (clearance number: EM 14/03/01); permission to conduct the research was granted and an application letter was written to the circuit for permission to collect data from the selected schools. Notices were then sent to the three identified schools to inform the principals about the research to be conducted in their schools. The researchers sought permission from the respective principals to conduct research in their schools. The researchers were aware that everything performed in life could be harmful, so they took steps to ensure that participants would not be harmed physically or emotionally. In this study, precautions were also taken to avoid exposing the participants to psychological harm. At the beginning of the data collection process, the participants were informed of the purpose and the potential impact of the study (Creswell 2013). The participants were made aware of the fact that their participation in the study was voluntary and they could withdraw from the study at any time if wished to do so (De Vos et al. 2011).

\section{Findings and discussion}

The findings of this study are aligned with the research questions and are presented in themes. The themes are illustrated by direct quotations from the participants followed by discussion that includes the literature on the focus of the study. The following questions were asked: What are the perceptions of teachers regarding the reasons for school absenteeism of orphaned children?, What are the challenges experienced when orphaned learners are absent from school? and, Who is responsible for ensuring that orphaned learners attend school?

\section{Perceptions of the causes of school absenteeism of orphaned children}

The teachers in this study identified physiological needs such as food, clothing and a lack of family and social support as causes of the irregular school attendance of orphaned children. The lack of family support seems to have a negative influence on the fulfilment of the physiological needs. The interview data show that teachers perceive poverty, financial hardship and a lack of resources such as food, books and school uniform as causes of absenteeism. One teacher said:

\footnotetext{
'You know that ... er, growing up without parents is very difficult. You find that sometimes the money is not there to cater for you and then maybe you find that parents left those learners without money. So we find that these learners face financial hardship. They lack funds to buy basic things like food, school uniform etc.' (Teacher $\mathrm{G}$, female, 1 year experience)
}

The above quotation suggests the lack of support from parents in providing for the educational needs of the learners as well as negligence in the role parents play to ensure that learners attend school. This finding is partially consistent with those in the literature, which emphasises poverty and economic hardship as the main reasons for the non-school attendance and school dropout of orphaned children (Kazeem \& Jensen 2017; Smiley et al. 2014; Tagurum et al. 2015). The researchers in this study are of the opinion that although the issue of poverty is real in some situations, there is a likelihood of inadequate care. The teachers who participated in this study spoke about orphaned children who are neglected by their guardians, including grand parents, who misuse orphan grants by buying alcohol or gambling it away instead of using the money to provide for the basic needs of the children. Without the fulfilment of needs such as food and a school uniform, learners are not able to attend school regularly. This finding is supported by the following quotation:

'From home, their guardians take the money; the little money that they get 'ba thiya dikarata ka tšona' meaning that they are playing gambling cards using the money. They use the grant money for gambling instead of buying food and clothes for the children. Other care givers use the money to buy beer and ends up drinking excessively.' (Teacher F, female, 1 year experience)

The researchers in this study argue that caregiving is an important aspect of childrearing and is crucial in the education of the children. The above quotation shows a gap in the care and support that the learners receive from home. The findings reveal that the participants have the perception that caregivers do not seem to prioritise education of the learners under their care. Such laxity could possibly be because of a lack of accountability of the caregivers in ensuring school attendance of the learners. Such implied accountability could create a sense of responsibility of the caregivers in ensuring school attendance of the learners. While there are recommendations in the literature for implementing strategies to alleviate poverty and provide resources so that orphaned children can attend school (Mwoma \& Pillay 2016), the findings of the current study suggest that the efforts to close the gap created by economic deprivation through child support grants are likely to be less effective where there is a lack of responsibility and accountability concerning the use of such resources by the caregivers to benefit orphaned children. According to Tanga (2013), caregivers misuse public funds or grants allocated for orphaned children, which has a negative impact on their education. In this study, the participants responses suggest negligence on the part of caregivers, deduced from how they gamble the grant money instead of using it for education. It is the assumption of the researchers of this study that there may be a culture of negligence and a lack of compassion for the welfare and education of orphaned children. Although the gambling behaviour of some caregivers may be the result of desperation from living in an impoverished socio-economic state and an attempt to generate money from gambling. Furthermore, using grant money for gambling instead of using it for education dilutes the governments' efforts in promoting the right to 
basic education of orphaned children. The lack of follow-up on how grant money is used implies a gap in the accountability of the caregivers and the government through social workers on the use of such resources. The teachers seem aware of this practice but it was not clear from this study if they report such incidences to social workers or not. Reporting such cases could be a way in which teachers may help the learners' in such situations.

The current study also found that insufficient support from the extended family is a factor that discourages learners from attending school. Most of the teachers participating in this study spoke about relatives, guardians and next-of-kin of the orphans not taking up the responsibility of ensuring that orphaned children attend school. The teachers mentioned that in some schools, physical abuse and excessive domestic chores were further reasons for school absenteeism. Teacher C said:

'Sometimes you find that orphaned learners are mostly abused. They are affected at home because, er, we find that people, er ..., living with them they instruct them to make unnecessary work because they have to do some jobs at home. And then, er, we find that early in the morning they wake up, er, they are tired and then they cannot come to school because of such abuse. Also the demand of the family cause even though they may not have the guardians at home, you find that there are lot of works to do.' (Teacher $\mathrm{C}$, male, 5 years' experience)

It seems that some caregivers or guardians lack the awareness of the demands of schooling on the learners' time as well as physical abilities. Excessive household chores are time-consuming and caused fatigue that may result in learners opting not to attend school. The lack of consideration for the well-being of the learners in terms of school attendance shows ignorance and devalues the importance of education. When orphaned children fail to attend school regularly because of physical abuse and carrying out excessive domestic chores - as revealed in this study and in the literature (Bamgboye et al. 2017; Majanga et al. 2015), a possible explanation could be the inability of caregivers to draw a line between orphans contributing to the welfare of the family and a lack of consideration and concern for the future of the orphaned children. As it seems that there are no procedures that require caregivers to account for their support for orphaned children in terms of their well-being and education, there is a need to re-visit the current policies and establish relationships between different government departments, such as basic education, social development, health and others, in terms of practical measures for ensuring accountability of learners' school attendance.

Apart from abuse in terms of household chores, the participants in this study indicated that many orphans are sexually abused, especially the girls who are raped by community members because of their vulnerability in the absence of an adult caregiver. What was surprising is that some orphaned children experience sexual abuse by family members and this prevents them from attending school. The following two quotations contain evidence of this:

'Mmm, the challenges that we experience is that they are raped sometimes by the people in the community. The people in the community may realise that there are no parents at or maybe guardians have gone to work. If the orphans are girls, they get raped and they miss classes. Then, they perform poorly in school. $\mathrm{Ok}$, in such cases we always call the social worker because we do not have the words that may comfort them. We even call the nurses. We call them just to talk to the learners so that they can realise that they are still loved.' (Teacher D, female, 25 years experience)

'The common kind of abuse we sometimes find is with the girl child. The kind of abuse that they experience is sexual abuse. Some of them are abusing drugs but the most serious one is sexual abuse. Which really takes away the virginity of these kids and as a result their future becomes bleak, it is like doomed because they do not come to school and concentration on schoolwork. Previously, a learner was doing Grade 6. She was twelve years old. A grant father also abused her sexually and she gave birth to a baby while she was still doing Grade 6. You can see how serious these type of abuse [are] more especially sexual abuse in our community.' (Teacher F, female, 1 year experience)

The researchers in this study view sexual abuse of learners as narrated in the above quotation as social and legal issues that have grievance implications for education. This finding suggests the lack of measures for implementing the consequences of sexual abuse and other anti-social behaviour in the community. The community seems not accountable for the psychosocial and physical health of the learners, which impacts on their school attendance. This study shows that sexual abuse also occurs in the community and within the family and is not limited to orphanages and child welfare institutions that have been reported in literature (Bode \& Goldman 2012; Euser et al. 2013; O'Dea 2008). From this finding, we state that sexual abuse is immoral, unacceptable and unlawful behaviour, which has negative influence on school attendance. Sexually abused learners may suffer from physical as well as psychological trauma which could affect their school attendance. Murray et al. (2014) also state that sexual abuse is a devastating experience and may cause long lasting emotional, psychological and physical harm to the victim. Sexual abuse may not only affect the schooling of orphaned children but it also changes the relationships between the orphan child and the caregivers. The role of the caregiver may change from being a provider and protector to being a physical, psychological and emotional abuser. Instead of being supportive, the relationships between orphaned children and abusers become hostile and threatening because of a lack of trust, fear, emotional trauma and bodily harm. The quotations of the participants in this study indicate their awareness of sexual abuse in the school community, what seems missing is that although the social workers come to school to check the school attendance of orphaned children, it is not clear if teachers share their awareness of sexual abuse in the community with the social workers. As researchers, we are asking if the teachers could possibly be held accountable for reporting such cases to social services or not? Is there a clear 
system and procedures in place that deal with such social issues that could have an impact on the school attendance of all children? It is possible that some community members may also be aware of learner abuse but because of a lack of Ubuntu, they are not taking the necessary action to help the learners.

Accountability theory states that there should be a system in place, goals and acceptable levels of achievements to guide behaviour. We as researchers in this study believe that there should be a system of care and measures in the community that protect children from sexual abuse to increase their chances of attending school. Such measures need to safeguard orphaned and vulnerable children from ill-treatment, violation and protection of their rights to dignity as well as their right to education. The measures or policy or guidelines should clearly stipulate who should be accountable for the assigned or expected task and responsibilities. In another study by Motsa and Morojele (2016), it was reported that orphaned children escape abusive situations at home when they attend school and that the orphans who do not attend school, because of abuse at home, miss this reassuring environment. This finding re-emphasises the value of attending school as well as the barriers to school attendance. In such cases, there is a need for accountability measures, which are based on stronger family values and cultural systems to protect orphans and other children from sexual abuse as well as to promote their right to education.

\section{Challenges experienced when orphaned learners are absent from school}

In this study, the teachers mentioned that some guardians and grandparents do not live with the orphans, while others do not cooperate when requested by the teachers to come to the school to discuss the absenteeism of the orphaned learners. According to the teachers, the guardians only come to school if the name of a social worker is mentioned. This finding suggests that the guardians probably attend meetings in order to continue receiving the grants without using the money to benefit the orphans. Two participants disclosed the following information:

'I have experienced that most of the guardians don't stay with the learners during the night. Some of them are alcoholics by nature and so they don't care about their children. They only come to school when you say that the social worker will be in school.' (Teacher B, female, 4 years' experience)

'Number one, you find that we lack the directives in terms of liaising with the guardians or the persons concerned. We find that the persons responsible for providing care as a guardian is not around at all. So when you want to talk with the guardian of the learner the contact is not there.' (Teacher E, male, 1 year experience)

A lack of knowledge concerning guardians who are responsible for obtaining grants or foster-grants on behalf of orphaned children is a challenging issue, especially when learning support resources are needed. According to two teachers:

'Someone accepts to take funds; when it comes to the education of the child we find that the person is not there and to ensure that the child comes to school. What I am saying is that the social workers first must liaised with the guardians and intervene at school level on behalf of these orphans to ensure that we reduce absenteeism of orphans.' (Teacher E, male, 1 year experience)

'The first support that we need is from the family. And the second one we need to share the problems of the learners. We need support in providing the learners with basic needs such as food, such as clothing and so on so that they can attend school.' (Teacher A, male, 4 years' experience)

This finding implies that the responsibility of ensuring that learners attend school should be a joint effort between the teachers and the caregivers or guardians. Such responsibility calls for a mutual relationship between the two parties that focuses on supporting the learner to attend school. Such a relationship of support seems lacking as reported by some teachers. These findings also indicate to some extent that there is a degree of negligence in the care that is expected from the guardians, including grandparents of orphaned children. Mwoma and Pillay (2016) state that parents and guardians of orphans and other vulnerable children need to be aware of the necessity of the children attending school regularly and of helping them with their homework. From this current study, it seems that there is a tendency of 'pseudo-care' or false pretence appearance for social services to access child support grants. The misuse of the social grants could be partially because of caregiver negligence and the lack of accountability in the effective use of grants for the welfare of the orphaned children. The reason for such behaviour could be because of the lack of follow-up by government officials or appointed community members on the welfare of the learners after the guardians receive the social grants. It is for this reason that we propose a need for accountability measures for teachers, caregivers, the community as well as different government departments in ensuring that orphaned learners attend school.

\section{Who is accountable for ensuring that orphaned learners attend school?}

On the question of who is responsible for ensuring that orphaned children attend school, this study found that teachers expect the Department of Education, as one of the stakeholders, to support them in providing the necessary resources to improve school attendance. The participants expressed the expectation that the Department of Education should provide structures in terms of guidelines and resources that could be used to support the education of orphaned children. They recommended the following:

'... the department should provide us with the resources that we require as a school to deal with these orphaned learners. We need the documents may be the guidance the guidelines of how to deal with these orphaned learners. This is of outmost important. (Teacher I/M/19)

Yaa, if maybe we can have a particular place where we can report these matters of orphaned learners maybe the government will assist in some other ways so that these learners can be the same as other learners.' (Teacher H, male, 21 years' experience) 
The above two quotations suggest a need for policy on managing the education of orphaned children. It is a possibility that there is uncertainty on how to address the school attendance of orphaned children caused by the gap created by the death of the parents. The lack of such guidelines could limit accountability concerning the school attendance of orphaned children. Apart from guidelines from the Department of Education, the teachers asserted that support was also needed from social workers to assist orphaned children to obtain social grants with which to buy basic needs so that they are able to attend school. The teachers also mentioned the need for the Department of Social Development to liaise with the Department of Education regarding the registration of guardians who receive social grants on behalf of the orphaned children. Teachers E and Teacher I confirmed this by adding:

'I think the direct support is that I wish and hope that the social development department can liaise with the education department in terms of the parenthood. In guardianship that is registered with the social department for helping the learners with child grant.' (Teacher E, male, 1 year experience)

'We need assistant from the social worker to grant this learner opportunity to get social grant to buy school basic things, which I have, already mentioned.' (Teacher I, male, 19 years' experience)

Teachers disclosed that in their schools, they get support from social services and this reduces the challenges of managing the school attendance of orphaned children. One teacher said:

'So when they come to school they ask those learners, they take them into a separate classroom, then they interviewed the learners about the relationship with the foster parents. So the interview is confidential place where we find that the learner is free to say everything that troubles him or her.' (Teacher F, female, 1 year experience)

Social workers appear to visit schools regularly to check on the attendance of orphaned learners. Some of the teachers spoke about sharing the problems experienced by orphaned learners with their foster parents and when they requested the caregivers to encourage the learners to attend school. One teacher said:

'We have got a register for all learners from all grades who are orphaned learners, such that every time like when people like NGO who normally come to visit our school frequently to check for these learners and even the Department of Social Work. They are always come to check these learners because they are paying them social grant and foster grant. They check that are they really come to school.' (Teacher D, female, 25 years' experience)

It seems that collaboration between the school and the Department of Education and Department of Social Services is needed to enable orphaned children to attend school. The integrated efforts between the different departments as well as the collaboration between schools, parents, members of the community and external agencies in supporting orphaned and vulnerable children have also been reported in other studies (Mwoma \& Pillay 2016; Wood \& Goba 2011). Despite the acknowledgement of the expectation of the role and contribution of each stakeholder in the education of orphaned children, the researchers of this article argue that there should also be measures of accountability. The accountability of the resources and services provided by these departments is important in ensuring that orphaned children receive the full benefit of government initiatives in supporting their education.

Another important finding was that the teachers who participated in this study were of the opinion that there is a need for support from the community in ensuring the safety of the learners by helping to monitor learners who roam around the community during school hours. The teachers also engaged neighbours to monitor attendance of orphaned children of guardians who work far from school:

'There are guardians who are working away from home. So we just go and talk to the neighbour to encourage the learner to come to school. We also make a record at school about the learner's attendance so that the learner who is not having the foster parents or guardian in the vicinity comes to school. We just monitor frequently monitor them in the morning. So that they must know that we kept an eye on them.' (Teacher B, female, 4 years' experience)

'We are also working with other voluntary organisation in the community, such as Thusalusaka (World Vision) and the Department of Social Work. So let us make these orphans feel at home as if they have parents. Let us share their experiences, let us solve their problems. Let us always be near them and give them the necessary support.' (Teacher $\mathrm{H}$, male, 25 years' experience)

The findings of this study show that teachers expect the community to prioritise and value the education of the children. In addition, they need to have a sense of children as belonging to the community to encourage collective responsibility in ensuring that all children attend school. The researchers in this study argue that this finding conceptualises community members not as bystanders but as active members in the education and welfare of the children in the community.

The teachers in this study use community-based structures to manage the absenteeism of orphaned learners. Some of the schools and the community members in this study seem to work together with NGOs to buy and provide for the basic needs of the orphans, such as uniforms and school bags, to help solve their non-attendance problems. Teachers expected NGOs to continue with the support they offer to orphaned learners, for example, buying them bicycles that they can use which may be an incentive to ensure that they attend school. Social workers are also expected to assist orphans with obtaining documents such as birth certificates so that they can access social grants. Two teachers are quoted below in support of these findings.

'... with our school we are having, er, World Vision, er, called Thusalusaka. It helps our learners with the uniforms. They come to school and make us identify the learners with problems or orphaned learners who don't have, er, basic needs. Like maybe if they don't have uniform as I mentioned they buy for them. And if they don't have school bags they do buy for them and then if 
there is need maybe these orphaned learner want go to secondary school they also go there and make the learners to identify them again, maybe help them with the uniform in other grades.' (Teacher A, male, 4 years' experience)

'For the learners who are living far from school, the NGOs try to buy bicycles for them to ride to school so that they do not have to walk long distances. This motivates them to attend school. We must also engage community structures like the Home Based Care people. The caring people local, we engage them to help these learners by caring for them even after the school, we have drop in centres where in we engage them to make sure that they are helped with doing homework so that they may be able to have the love of coming to school the next day. Then we must also adopt orphaned learners who may encourage them to attend school.' (Teacher $C$, male, 5 years experience)

This finding implies the need to reach out for external support which the researchers in this study argue is not the ultimate solution if there is no accountability in ensuring that the resources support the learners' welfare and school attendance. The participants mentioned working with a volunteer organisation in the community and social workers. This collective and collaborative responsibility needs structured accountability measures to ensure that the orphaned children attend school.

\section{Conclusion}

This study has explored the perceptions of teachers on how school stakeholders respond to the school attendance of orphaned children. The findings show that there is an absence of accountability measures in the provision of the basic needs and psychosocial care of the learners that contributes to their ability to attend school. The teachers conceptualise the community as active members in the education and welfare of orphaned children and not as bystanders. The participants also recognised orphaned children as belonging to the community and expect collaborative responsibility in ensuring that the children attend school. The findings of the study indicate inadequate moral responsibility, family values and care as well as the need for accountability of resources on the part of the community, government and NGOs in supporting the education of orphans and other vulnerable children.

There is strong evidence in the relevant literature concerning the lack of physical and material resources as being reasons for the irregular school attendance of orphaned children. This study identifies poor social and emotional care as other reasons for school absenteeism. In this article, it is argued that policy and the provision of resources alone cannot address the problem of school absenteeism of orphaned learners but that there should be a combined and clearly stated accountability of school stakeholders, including caregivers, communities, the government and NGOs among others. It is further suggested that without explicit accountability in terms of introducing relevant measures and the subsequent consequences of insufficient support from caregivers, learner absenteeism may remain problematic despite the availability of material and psychosocial support. Therefore, it is imperative that the silence in policy and in practice regarding who should be held accountable for the school attendance of orphaned learners and other vulnerable children should be addressed.

This article draws attention to the need for collaborative efforts from the different stakeholders in education to ensure that orphaned children receive quality education. For such efforts to be effective, accountability measures should be put in place and there has to be a stronger sense of responsibility among the different stakeholders. Stakeholder accountability in terms of the socio-economic, safety and emotional needs of the learners is likely to contribute to a more enabling environment that encourages the school attendance of orphaned and other vulnerable children. There is a need for accountability strategies that are grounded in strong family values and cultural systems to ensure a better future for orphaned children through education. The misuse of social grants and the false pretences of caregivers in order to access social grants imply a culture of a lack of trust, negligence and deteriorating family care. There is an absence of accountability for the effective use of grants for the welfare and education of orphaned children.

\section{Acknowledgements}

The research for this article was done by the authors. We are grateful to all the participants who shared their experiences with us. We are also thankful for the valuable comments from the reviewers which helped in improving the quality of this paper.

\section{Competing interests}

The authors declare that they have no financial or personal relationships that may have inappropriately influenced them in writing this article.

\section{Authors' contributions}

T.A.O. made substantial contributions in the conceptualisation of the study. She supervised the implementation of the study and assisted in the data collection and analysis as well as the writing up and critical revision of the manuscript. N.M.R. made a substantial contribution to the literature search, data collection and drafting of the manuscript.

\section{Funding information}

No external funds were received to conduct this study. The researchers used their own personal resources for this study.

\section{Data availability statement}

Data sharing is not applicable to this article as no new data were created or analysed in this study. 


\section{Disclaimer}

The views and opinions expressed in this article are those of the authors and do not necessarily reflect the official policy or position of any affiliated agency of the authors.

\section{References}

Abebe, T. \& Aase, A., 2007, 'Children, AIDS and the politics of orphan care in Ethiopia: The extended family revisited', Social Sciences \& Medicine 64(10), 2058-2069. https://doi.org/10.1016/j.socscimed.2007.02.004

Ardington, C. \& Leibbrandt, M., 2010, 'Orphanhood and schooling in South Africa: Trends in the vulnerability of orphans between 1993 and 2005', Economic Development and Cultural Change 58(3), 507-536. https://doi.org/10.1086/650414

Bamgboye, E.A., Odusote, T., Olusanmi, I., Nwosu, J., Phillips-Ononye, T., Akpa, O.M. et al., 2017, 'School absenteeism among orphans and vulnerable children in Lagos State, Nigeria: A situational analysis', Vulnerable Children and Youth Studies 12(3), State, Nigeria: A situational analysis', Vulnerable Children and

Bennell, P., 2010, 'The impact of aids epidemic on the schooling of orphans and other directly affected children in sub-Saharan Africa', The Journal of Development Studies 41(3), 467-488. https://doi.org/10.1080/0022038042000313336

Bode, A. \& Goldman, J.D.G., 2012, 'The impact of child sexual abuse on the education of boys in residential care between 1950 and 1975', Pastoral Care in Education 30(4), 331-344. https://doi.org/10.1080/02643944.2012.702780

Bonthuys, E., 2010, 'Legal capacity and family status in child-headed households' Challenges to Legal Paradigms and Concepts 6(1), 45-62. https://doi.org/10.1017/ S1744552309990292

Campbell, C., Andersen, L., Mutsikiwa, A., Madanhire, C., Nyamukapa, C. \& Gregson, S., 2016, 'Can schools support HIV/AIDS-affected children? Exploring the "ethic of care" amongst rural Zimbabwean teachers', PLoS One 11(1), 1-22. https://doi. org/10.1371/journal.pone.0146322

Cohen, L., Manion, L. \& Morrison, K., 2011, Research methods in education, Routledge, New York.

Creswell, J.W., 2013, Research design: Qualitative, quantitative, and mixed approaches, 4th edn., Sage Publication, Thousand Oaks, California, US.

Crowe, M., Maree, I. \& Porter, R., 2015, 'Conducting qualitative research in mental health: Thematic and content analyses', Australian \& New Zealand Journal of Psychiatry 49(7), 616-623. https://doi.org/10.1177/0004867415582053

Dalen, N., 2009, 'Challenges for orphans in sibling headed households. Assessment of interventions to reduce stigma in Rakai District, Uganda', The Norwegian Medical Society 6, 191-209.

Darago, J., 2016, 'Are there really 153 million orphans worldwide? The hope effect', viewed 20 May 2018, from hopeeffect.com/153-million-orphans.

Department of Education, 2010, National policy on learner attendance, Gazette No. 33150, Government Printers, Pretoria.

Department of Social Services, 2013, Framework for social welfare services, Government Printers, Pretoria.

De Vos, A.S., Strydom, H., Fouche, C.B. \& Delport, C.S.L., 2011, Research at grass roots, 4th edn., Van Schaik, Pretoria.

Euser, S., Lenneke, R.A., Alink, L.R.S., Tharner, A., Van Zendoorn, M.H., Marian, J. et al., 2013, 'The prevalence of child sexual abuse in out-of-home care: A comparison between abuse in residential and in foster care', Child Maltreatment 18(4) 221-231. https://doi.org/10.1177/1077559513489848

Foster, G., 2002, 'Understanding community response to situation of children affected by AIDS: Lesson for External Agencies', in Draft Paper prepared for the UNRISD Project HIV/AIDS and Development, March 2002, pp. 1-28, Harare, Zimbabwe.

Ganga, E. \& Maphalala, M.C., 2013, 'Cognitive learning: A life-line challenge for orphans and vulnerable children in child-headed households', Journal for Socia Science 36(1), 49-58. https://doi.org/10.1080/09718923.2013.11893172

ISRN Public Health, viewed 09 February 2018, from https://doi.org/10.1155/ 2013/518328

Joubert, R. \& Prinsloo, S., 2009, The law of education in South Africa, 2nd edn., Van Schaik, Pretoria.

Kazeem, A. \& Jensen, L., 2017, 'Orphan status, school attendance, and their relationship to household head in Nigeria', Demographic Research 36(22), 659-690. https://doi.org/10.4054/DemRes.2017.36.22

Majanga, E., Mukonyi, P. \& Vundi, S., 2015, 'Socio-pedagogical challenges facing orphaned and vulnerable children in the aftermath of the 2007-2008 election violence in Nakuru County, Kenya', Journal of Education and Practice 6, 155-160.

Mohlakwana, M.A.U., 2013, 'Care and support children in schools: The case of childheaded families', South African Journal of Social Sciences 36(1), 11-18. https:// doi.org/10.1080/09718923.2013.11893168

Moletsane, M., 2013, 'Educational and psychosocial effects of AIDS on orphans from a previously disadvantaged South African township', Journal of Human Ecology 44(3), 297-303. https://doi.org/10.1080/09709274.2013.11906670

Motsa, N.D. \& Morojele, P.J., 2016, Vulnerability and children's real-life schooling experiences in Swaziland', Educational Research for Social Change 5(2), 35-51. https://doi.org/10.17159/2221-4070/2016/v5i2a3

Murray, L.K., Nguyen, A.M.A., Judith, A. \& Cohen, J.A., 2014, 'Child sexual abuse', Child Adolescence Psychiatry Clinic 23(3), 321-337. https://doi.org/10.1016/j. chc.2014.01.003
Mwoma, T. \& Pillay, J., 2015, 'Psychosocial support for orphans and vulnerable children in public primary schools: Challenges and intervention strategies', South African Journal of Education 35(3), 1-9. https://doi.org/10.15700/saje.v35n3a1092

Mwoma, T. \& Pillay, J., 2016, 'Educational support for orphans and vulnerable children in primary schools: Challenges and interventions', Issues in Educational Research 26(1), 82-97, viewed 14 March 2018, from http://www.iier.org.au/ iier26/mwoma.pdf

Myong, L.J., Seongseop, K.S. \& Wansoo, K., 2012, 'Service employees' organisational citizenship behaviour and customer-oriented behaviour: An accountability theoretical perspective', Journal of Food Service Business Research 15(4), 335-361. https://doi.org/10.1080/15378020.2012.706490

National Policy Act, 1996, Policy on learner attendance, Government Gazette No. 33150, Notice 361, Government Printers, Pretoria.

Nieuwenhuis, J., 2011, Qualitative research designs and data gatherings techniques, Van Schaik, Pretoria.

O'Dea, M.G.F., 2008, 'The history and consequences of the sexual-abuse crisis in the Catholic Church', Studies in Gender and Sexuality 5(1), 11-30. https://doi. org/10.1080/15240650509349238

Ombuya, B.D., Onyango, Y.J.M. \& Omolo, T.M., 2012, 'Effects of orphan hood on girl-child's access and retention in secondary school education: A case of Rongo District; Kenya', International Journal of Academic Research in Progressive Education and Development 1(4), 114-136.

Operario, D., Cluver, L., Rees, H., MacPhail, C. \& Pettifor, A., 2008, 'Orphanhood and completion of compulsory school education among young people in Southern Africa: Findings From a National Representative Survey', Journal of Research on Adolescence 18(1), 173-186. https://doi.org/10.1111/j.1532 7795.2008.00555.x

Pillay, J., 2012, 'Experiences of learners from child headed households in a vulnerable school that makes difference', School Psychology International 33(3), 3-21. https://doi.org/10.1177/0143034311409994

Republic of South Africa, 1996, The South African Schools Act (Act 84 of 1996), Government Printer, Pretoria.

Republic of South Africa, 2003, The Constitution of the Republic of South Africa (Act 108 of 1996), Government Printer, Pretoria.

Schlenker, B.R., 1986, Personal accountability: Challenges and impediments in the quest for excellence, Technical Report for the Navy Personnel Research and Development Center, San Diego, CA.

Schlenker, B.R. \& Weigold, M.F., 1989, 'Self-identification and accountability', in R.A. Giacalone \& P. Rosenfeld (eds.), Impression management in the organization, pp. 21-43, Lawrence Erlbaum Associates, Hillsdale, NJ.

Shann, M.H., Bryant, M.H., Brooks, M.I., Bukuluki, P., Muhangi, D., Lugalla, J. et al., 2013, The effectiveness of educational support to orphans and vulnerable children in Tanzania and Uganda, Hindawi Publishing Corporation, Dar es Salaam, Tanzania.

Smedley, S. \& Pepperell, S., 2010, 'No man's land: Caring and male student primary teachers', Teachers and Teaching: Theory and Practice 6(3), 259-277. https://doi. org $/ 10.1080 / 713698737$

Smiley, A., Omoeva, C., Sylla, B. \& Chaluda, A., 2014, Orphans and vulnerable children Trends in school access and experience in Eastern and Southern Africa, Educational Policy and Data Center, Washington, DC.

Statistics South Africa, Census, 2011, Municipal report Limpopo province, Report 0301-57, Statistics South Africa, Pretoria.

Tagurum, Y.O., Chirdan, O.O., Bello, D.A., Afolaranmi, T.O., Hassan, Z.I., Iyaji, A.U. et al., 2015, 'Situational analysis of orphans and vulnerable children in urban and rural
communities of Plateau State', Annals of African Medicine 4(1), 18-24. https:// communities of Plateau State', Anno
doi.org/10.4103/1596-3519.148714

Tanga, P.T., 2013, 'The impact of declining extended family support system on the education of orphans in Lesotho', African Journal of AIDS Research 12(3), 173-183. https://doi.org/10.2989/16085906.2013.863217

The Local Government Handbook South Africa, 2017, Mopani District, Sponsored Profile, Government Printing Press, viewed from www.municipalities.co.za.

UNICEF (United Nations Children's Fund), 2009, Promoting quality education for orphans and vulnerable children. A sourcebook for programme experiences in Eastern and Southern Africa, UNICEF ZAMBIA, New York.

UNICEF (United Nations Children's Fund), 2017, Monitoring the situation of children and women. The state of the world's children 2017 statistical tables, viewed 19 May 2018, from https://data.unicef.org/Resources)Uncategorized.

USAID, 2008, Supporting highly vulnerable children: Progress, promise and partnership, Second Annual Report to Congress Report, U.S. Agency for International Development, Washington, DC.

Van Rooyen, D., Frood, S. \& Ricks, E., 2012, 'The experiences of AIDS orphans living in a township', Health SA Gesondheid 17(1), 1-11. https://doi.org/10.4102/hsag. v17i1.568

Wood, L. \& Goba, L., 2011, 'Care and support of orphaned and vulnerable children at school: Helping teachers to respond', South African Journal of Education 31(2), 275-290. https://doi.org/10.15700/saje.v31n2a484

World Health Organization (WHO), 2004, The importance of caregiver-child interactions for the survival and healthy development of young children: A review, World Health Organization, Geneva.

Xiaoming, T., Yunfei, L.V., Xiaoming, L., Xiaoyi, F., Guoxiang, Z., Xiuyun, L. et al. 2009, 'School performance and school behaviour of children affected by AIDS in China', Vulnerable Child \& Youth Studies 4(3), 199-209. https://doi.org/ 10.1080/17450120902814420 